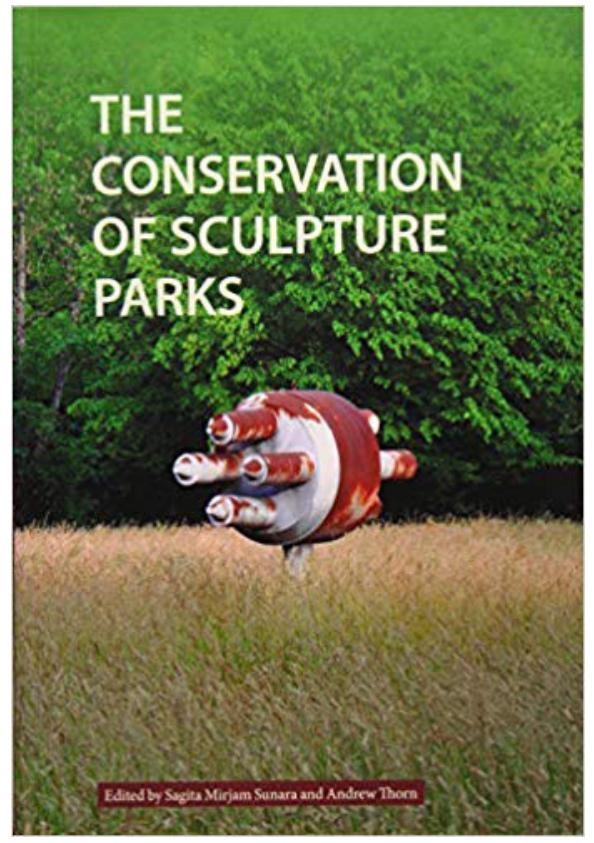

\title{
The Conservation of Sculpture Parks
}

\author{
Editor: Sagita Sunara, Andrew Thorn \\ London: Archetype Publications, 2018 \\ ISBN: 9781909492585
}

Dimensiones: 245 x $170 \mathrm{~mm}$

Páginas: 192

Los "parques de esculturas", o como es más habitual denominarlos en español, "museos al aire libre", son un tipo de bienes (o conjunto de bienes) patrimoniales que presentan unas características muy particulares. Son espacios entre medias de los conceptos de museo y de paisaje cultural, en los que las obras (normalmente escultura contemporánea, que en muchos casos ha sido creada ex profeso para su ubicación precisa) se relacionan e interaccionan, tanto plástica como físicamente, con un entorno natural o arquitectónico más o menos modificado. Fruto de esta situación particular surgen problemas de conservación y gestión también particulares, derivados de la exposición a la intemperie, los materiales utilizados, el tamaño de las áreas a considerar, la valoración y apreciación (o falta de la misma) del público, vandalismo, etc. Todos estos aspectos imponen condicionantes y particularidades a la hora de plantear las intervenciones de conservación (preventiva o curativa) y de restauración.

Para tratar esta problemática en un caso específico, el de 38 esculturas que fueron producidas e instaladas alrededor de la fábrica de Sisak Steelworks, en Croacia (aun como parte de Yugoslavia durante su creación), se convocó el congreso internacional SPark: Conservation of Sculpture Parks en septiembre de 2015. Este congreso fue parte de un proyecto de conservación de este conjunto, del que se encargó el departamento de conservaciónrestauración de la Academia de Artes de Split. El libro que hoy revisamos, "The Conservation of sculpture parks" recoge contribuciones presentadas en dicho congreso. El libro está editado por Sagita Mirjan Sunara, del citado departamento de conservación-restauración, y por Andrew Thorn, de la empresa Artcare de Australia.

En muchos casos, los libros de actas de congresos son, por su origen, heterogéneos en contenidos y resulta difícil encontrar el mismo interés en todos los capítulos. En este caso, sin embargo, al ser fruto de un congreso con un foco muy claro y delimitado, los trabajos presentan una notable unidad temática. Los 14 capítulos presentan fundamentalmente estudios de caso de parques de escultura de Europa, América del Norte y Australia. En su mayoría son parques de escultura contemporánea, con las excepciones del cementerio de Biedermeier en Viena y del jardín barroco del castillo de Frederiksborg en el norte de Copenhague. Los trabajos abordan tanto los problemas de deterioro de los distintos materiales (bastantes en metal, aunque también otros materiales de construcción como piedra o morteros, e incluso materiales más perecederos como madera), como los derivados de aspectos sociales y culturales, incluyendo la relación con los artistas o la intencionalidad de los mismos en el momento de la creación del conjunto.

El libro se cierra con un interesante resumen de la mesa redonda celebrada en el congreso bajo el título "Reviving neglected sculpture parks in Croatia", que si bien no es un sumario del resto del libro, sí que sirve muy bien como recapitulación de ciertos aspectos abordados en los distintos trabajos, especialmente aquellos relacionados con la necesidad de mantenimiento, la gestión, la interacción con el público y el potencial de estos espacios para el desarrollo turístico, económico y 
social.

En resumen, se trata de un libro muy interesante para los profesionales de la conservación interesados en este tipo de bienes. De los múltiples casos expuestos se pueden extraer numerosas lecciones que pueden ayudar a abordar la complejidad de la conservación de los parques de esculturas.

\section{Emilio Cano}

Centro Nacional de Investigaciones Metalúrgicas

(CENIM)-(CSIC) 